\title{
Acoustic Insulation And Building Information Modeling: A Model Of Calculation For The Code Checking In The Forecast Phase And Of Measurement Of Performance
}

\author{
Costantino Carlo Mastino ${ }^{1}$, Roberto Baccoli ${ }^{1}$, Andrea Frattolillo ${ }^{1}$, Martino Marini ${ }^{2}$, Chiara Salaris ${ }^{1}$ \\ ${ }^{1}$ DICAAR University of Cagliari, Cagliari, Italy \\ ${ }^{2}$ DADU University of Sassari, Alghero, Italy
}

\begin{abstract}
The acoustic performance is more and more often a requirement in the construction of both private buildings and public buildings. Internationally, over the last few years we have witnessed the revision and issue of new standards relating to the project phase (calculation of the performance) based on the ISO 12354 series, and the postbuilding verification phase based on ISO 16283 standards. Fundamental aspects to achieve high performance consist of achieving a level of details that is increasingly high and shareable. Building information modeling, in addition to being mandatory for some types of work, is increasingly used by designers and construction companies, to gain greater knowledge of the specific case in particular and of methods of execution. In the present work a calculation code is presented which, taking advantage of the BIM model information, allows the calculation of the performance, the check of the legislative limits and the integration of the post-building data instrumentally recorded. Finally the code was tested on the considered case study and monitored in the different building phases.
\end{abstract}

\section{Introduction}

Increasingly BIM is used for purposes other than the main processing applications for which it had been initially created. Aim of the present study was that of employing the open IFC format of BIM model for the acoustic aspects concerning project and instrumental check. The BIM model was employed by taking advantage of geometrical data and performance information for building components contained in it and then storing the same model the results achieved at the different stages:

- DESIGN: prediction of acoustic performance;

- CONSTRUCTION: measured data during the construction;

- COMPLETION: measured data after completion).

In the present research a calculation model, which enables the analysis of specific geometries depending on defined acoustic zones, has been defined. It starts from a digital model of the building in the IFC format, by defining a list of elements auditable in an acoustic perspective for which a prediction calculation of performance could be carried out according to ISO 12354 standard (ISO,2013;ISO 2017 part 1,2,3; ISO 2009) and to which measurement data for proof test at completed work could be awarded according to the various standards (ISO, 2014; ISO, 2015; ISO,
2016; UNI, 2010; UNI 2012). The encoding of BIM model and its implementation into the developed model has to be regarded as an important issue of the present work.

The codification can be performed in different ways both with proprietary coding systems and with internationally recognized coding systems such as the Uniclass or Ommiclass system. In particular, the Uniclass system, adopted in the UK, was updated in 2015 to be compatible with BIM systems. As a main result of the BIM Toolkit project, NBS has collaborated with experts from industry to develop the new classification system. Uniclass 2015 provides:

- A unified classification system for the construction industry. For the first time, buildings, landscapes and infrastructures can be classified into a unified scheme;

- A hierarchical suite of tables that support classification from a university campus or from a road to a TILE network;

- A numbering system sufficiently flexible to meet future classification requirements;

- A system conforming to ISO 12006-2 that is mapped to NRM1 and supports mapping to other classification systems in the future.

Uniclass 2015 is subdivided into a series of tables that can be used to categorize information for costs, briefing, CAD layering, etc., as well as to prepare specifications or other production documents such as the those for whole process concerning the design and verification of acoustic performance.

The research objective was that of assessing whether the use of BIM model in the different stages of the construction process brings advantages or drawbacks with respect to a traditional approach. The implementation of what included in reference standards into the developed computational model has shown that the use of a BIM model entails substantial benefits in the different stages of predictive (ISO 12354), and survey calculations (ISO 16283). It shortens the execution times detecting in a simpler way the critical elements on which possible instrumental tests have to be carried out.

\section{The digital process for buildings}

Nowadays the work request for buildings or infrastructures is everywhere closely linked to the buildout speed and to the efficiency of design work. Efforts to improve implementation and efficiency are quite heavy 
within a market defined by narrow margins, lack of competence and complicated supply chains. In global market economy with quickly evolving technologies, clear and precise rules are often needed to help public administration to adapt to change and to innovate successfully. International or national standards can help to establish the above rules. A specific example is given with the rules concerning BIM (ISO,2013), i.e. Building Information Modeling. The digitization of the design, building and management process for real estates is not a new concept. On previous occasions architects and engineers were obliged to go from drafting tables to CAD, from the physical to the virtual pencil. It was a groundbreaking step forward with not a few problems. The BIM had already been theorized as procedural concept for buildings in the '70s. The BIM methodology (Kim et al, 2013; Kirkegaard et al , 2017; Richard et al , 2013; Wu e al., 2010; Marini et al., 2015) includes digital representations of the physical and operational characteristics of a work, through supporting models, to all operators in the building sector, in all phases of the life cycle of the aforementioned work. Many positions, from the computer technician to the fire fighter, from the sanitation worker to the estate agent, in addition to the those established, will face such a methodology. Recently we are witnessing the birth of several devices in the BIM perspective in order to foster such a revolutionary process. It is clear that the interoperability between softwares and operator is essential, as well as the need of integrate increasingly data from different professional learnings, other than from various proprietary softwares started a number of initiatives aimed at the open BIM. In such a perspective, the International Alliance for Interoperability, now called buildingSMART International (building-SMART, 2018), has been developing the Industry Foundation Classes (IFC) defining by them the specifications for an open and freely available format. The IFC format allows the interchange of an information model without any loss or distortion of the data included and it has been designed to this end, to draw up all information concerning the building, over its entire life-cycle, from the feasibility studies until its construction, maintenance and disposal or refurbishment, passing through all the phases of project and planning. Furthermore the IFC specifications have been transposed into the ISO 16739 standard (ISO,2013). One of the key issues of Building Information Modeling, as outlined in Figure 1, consists of representing geometrically and graphically the building by means of a 3D model to which functional, performance and operational knowledge can be linked during the different phases of the Building life. More generally all information inherent in the building at different levels and for different purposes are linked.

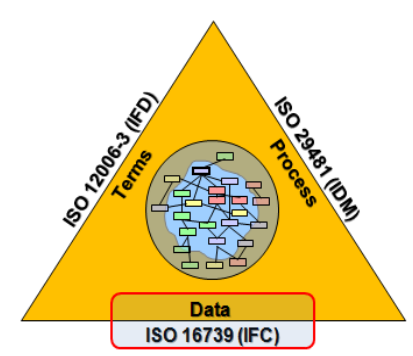

Figure 1: Organization of the data structure within BIM IFC format of BuildingSMART.

Even though BIM has arisen because of economic issues mainly tied to the savings made during the operation phase of a building, named by some authors as BOOM (Building Operation Optimization Model), more and more often the BIM model is tried to be used in BPS (Building Performance Simulation), in order to assess the building performance at design phase. The typical processes to generate the simulation models for physical aspects, as the simulation of acoustic requirements, are usually time-consuming and prone to errors or to inaccuracies due to various issues. Essentially these typical processes reproduce data already existing because of other issues, with specific reference to models usually generated for the architectural counterpart. The possible utilization of an architectural model, already crowded with the performance data concerning other elements, to different simulations and analyses has several advantages. The benefits of such a process, automatic or semiautomatic, as testified for other example of passage BIM a BPM [Mastino et al.,2017a), can be summarized in four items:

- 1) riducing the amount of time and of needed costs to develop a model for the physical simulation of the building in question,

- 2) enabling a rapid generation of design options,

- 3) improving the accuracy of BPMs (Building Performance Modeling simulation)

- 4) achieving buildings marked with performance substantially higher than those corresponding to building realized by following a traditional designing process.

\section{Methods for verifying the digital model}

In digital procedures a leading role is played by Model Checking thanks to which projects can be verified and validated not only in the design phase but during all the process steps in order to ensure completeness, transmissibility and consistency of all data and information. The control has to start from an initial precheck, called BIM Validation, to ensure reliable results. Such precheck has to verify the information content of the BIM model and then proceed with further analyses as Clash detection and the Code checking. This means that the BIM model has to be the result of a thorough modeling process in order to make possible the validation of the graphic and non graphic content with the aim of ensuring reliable data for the following steps of the process. The check process of a model will be helpful to customers to verify that the model includes all the 
attributes requested in the EIR (Employer Information Requirements) and developed in the OPM (Operational Plan for Management). In the same way BIM is a basic tool for the individual developer and for the whole working group. Indeed, thanks to the use of IFC format it is possible to bring together in a single model the various projects coming from different branches (architectural, engineering, installations) to detect possible clashes or mutual inconsistencies and correct them virtually for the purpose of bringing forward the set of problems that otherwise would occur in the construction yard where everything is more difficult and expensive. In the EIR and in the OPM the "rule set" must be specified, it is about the set of control rules that are applied to the model, which are subdivided into three check steps: "the rules for the management of information interferences" (clash detection), " the rules for standard verification" (BIM Validation), and "the rules for the management of information inconsisten-cies" (code checking).

With respect to the building acoustic performance the code checking is essential (Marini et al, 2018, Mastino et al, 2017b). Indeed just in this check step we ascertain if the building component (walls, slabs, windows etc), comply with the performance limit required in the standard. For instance in this phase it is ascertained if a given wall complies with the Rw value required by the EIR or by specific standards. This phase concerns also the check, both predictive and in situ at completed work, of passive acoustic requirements. Moreover it is about the verification, both predictive and at finished work, of the acoustic passive requirements and by means of such a procedure both the developer and the works director will have to ascertain respectively, the former the compliance of calculation with what is imposed with national rules, and the latter will have to ascertain the results of in situ measurements at completed work are conform to the standard in force. The data structure needed to the code checking with regards to acoustic performance is presented in Figure 2.

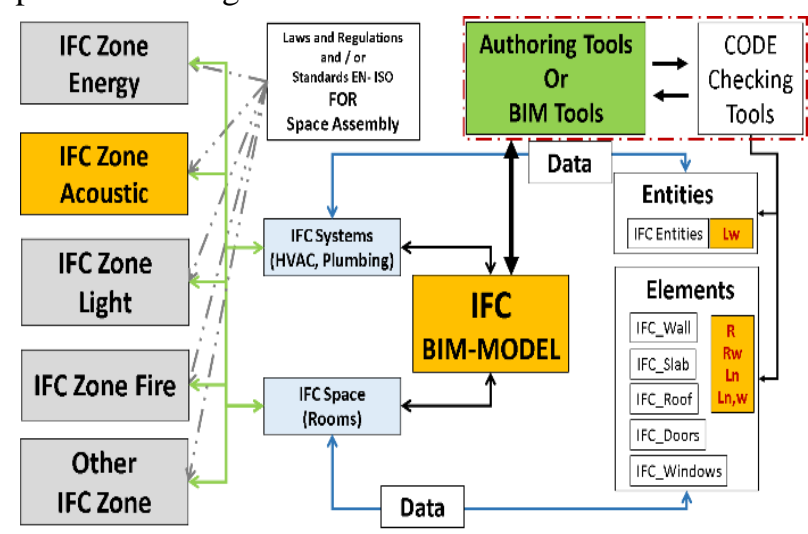

Figure 2: Organization of data structure in the BIM IFC format as the acoustic performance is concerned.

- The code checking is carried out during the different phase (designing, construction or completed work) by applying different reference standards which involve the prediction calculation (ISO,2013;ISO 2017 part $1,2,3$; ISO 2009) or in field instrumental measurements (ISO, 2014; ISO, 2015; ISO, 2016; UNI, 2010; UNI 2012).to assess the performance indicators. The benefits of data exchange from BIM to BPM by automatic semi-automatic procedures had been already expected by Bazjanac (2001) who highlighted time savings reaching $75 \%$ in creating the building geometry in case of smalll and medium size through a proper implementation of automated processes. In acoustic terms the use of BIM to generate the BAM (Building Acoustic Modeling) is currently subject of study on the part of researchers and software manufacturers. Three main steps are needed to implement this methodology:

- 1)importing or creating the building geometry, zoning and applicable data into the IFC model tby means of BIM Tools or Authoring Tools;

- 2) checking geometry and imported data, correcting possible errors and integrating possibly missing information for the specific purpose;

- 3) carrying out the verification of performance parameters (prediction calculation or setting th resuts form in situ measurements).

What is reported in the previous points is summarized in figure 3 where starting from the BIM model all the various steps are performed.

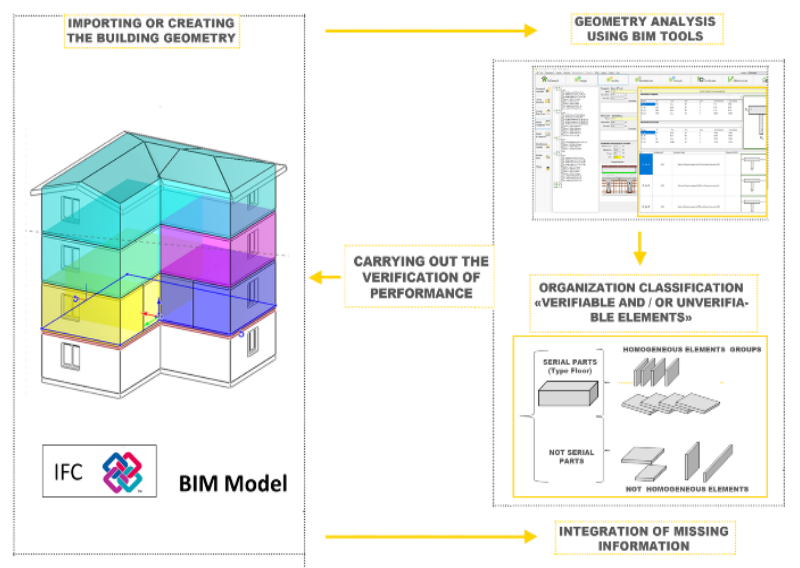

Figure 3: Use of BIM in design and testing of acoustic performance.

\section{Key aspects of the component analysis process}

A substantial part of the analysis process of the BIM model described is the evaluation of the geometry in order to identify all the elements subject to both predictive calculation and instrumental verification. This verification must be carried out according to the different reference standards (Di Bella et al., 2017). A schematization of the results of this analysis is shown in Figure 4. The developed model is capable, after analyzing the geometry, to return a complete list with all the audutable elements, identifying the type of verification to be performed. 


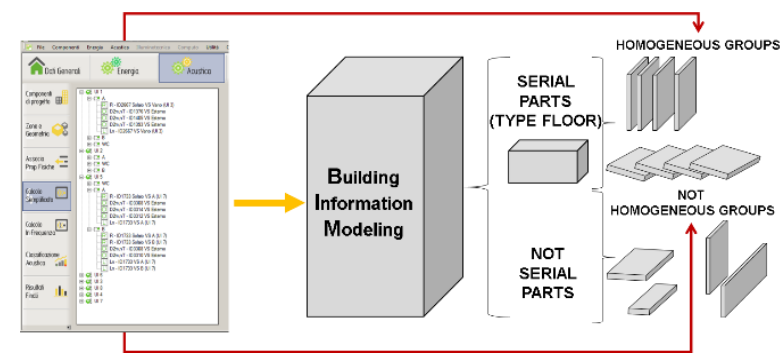

Figure 4: Detection of the auditable elements and their type.

The detection of the auditable elements includes the analysis and identification of the boundary conditions such as, for example, the identification of the connected rooms and of the elements related / connected to the element analysis. This required identification is summarized in figure 5

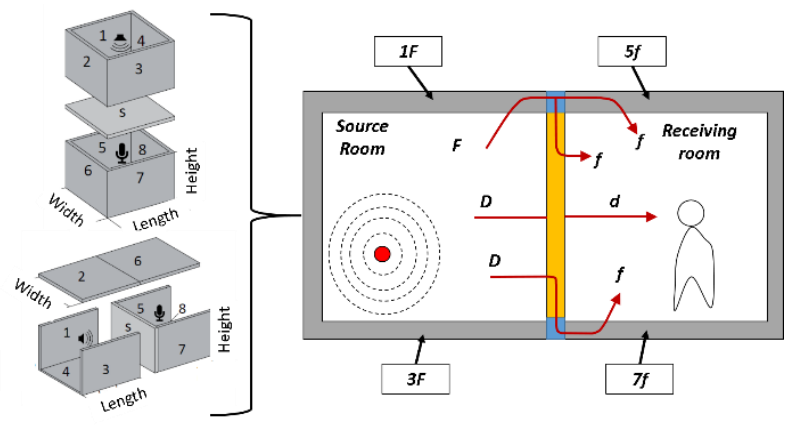

Figure 5: Identification of boundary conditions.

In figure 5, in the drawings on the left, the element under analysis is indicated with the letter "s". The same object is shown on the right highlighted in yellow. The elements numbered 1 to 8 represent the boundary conditions to be known for the calculation. Normally, to indicate the transmission path through the boundary elements, the capital letter " $F$ " is used for the source side and the lower case " $\mathrm{f}$ " for the receiving side, while for the transmission path through the analysis element the letter "D - $d$ " is adopted.

\section{Acoustic performance and developed calculation model}

The calculation model devised and developed in the present research is capable to manage simultaneously various physical aspects related to the design and auditing of buildings. Another specification is the interfacing / interoperability with the geometric model generated with the aid of a BIM oriented software. The model, created using the Visual Studio environment, was written using $\mathrm{C}++$ object-oriented programming and mainly $\mathrm{C \#}$ language; the model has a size of about 50,000 lines. The calculations are carried out mainly according to the procedures established by the various UNI, EN and ISO standards. The implementation of the model also involved the development of a graphical interface that allow the operator to comply with the requirements of the different algorithms. The model was provided with an open source graphical display for geometry freely available in the web and called "IFC Viewer" . It allows to graphically display the content of BIM files written in IFC format

\section{Predictive calculation and classification}

The predictive calculation model is governed by the equations of the recently modified ISO 12354 standard and partly by the UNI 11367 standard which describes a methodology for acoustic classification. The following are the main equations that govern the implemented calculation model:

$$
\begin{aligned}
& R^{\prime}=-10 \log \tau^{\prime} \quad[d B] \\
& \tau^{\prime}=\tau_{d}+\sum_{f=1}^{n} \tau_{f}+\sum_{e=1}^{m} \tau_{e}+\sum_{s=1}^{k} \tau_{s}
\end{aligned}
$$

where:

- $\tau$ 'is the transmission factor defined as the ratio between incident power and total power transmitted from the opposite side of the building to the receiving environment;

- $\tau_{\mathrm{d}}$ is the transmission factor that includes the contribution given by the Dd and Fd paths;

- $\tau_{\mathrm{f}}$ is the transmission factor that includes the contribution given by the Fd and Df paths;

- $\tau_{\mathrm{e}}$ is the transmission factor due to airborne noise that affects the wall and is directly transmitted to it in the receiving environment;

- $\tau_{\mathrm{s}}$ is the indirect transmission factor by air due to transmission via a s system (for example side walls and adjacent environment).

Equations 3 and 4 represent airborne noise transmission between the different environments.

$$
\begin{gathered}
L_{n}^{\prime}=10 \log \left(10^{\frac{L_{n, d}}{10}}+\sum_{j=1}^{n} 10^{\frac{L_{n, i j}}{10}}\right)[\mathrm{dB}] \\
L_{n}^{\prime}=10 \log \sum_{j=1}^{n} 10^{\frac{L_{n, i j}}{10}}[\mathrm{~dB}]
\end{gathered}
$$

where:

- $\mathrm{L}_{\mathrm{n}, \mathrm{d}}$ is the sound pressure level normalized by direct transmission, in decibels;

- $\mathrm{L}_{\mathrm{n}, \mathrm{ij}}$ is the sound pressure level normalized by lateral transmission, in decibels;

- $\mathrm{n}$ is the number of elements

Equations 3 and 4 represent the transmission of the noise that takes place following a structural way, between overlapping and adjacent environments respectively.

Finally, equation 5 represents the transmission of noise from the outside towards the internal environment in terms of sound insulation offered by the portion of the façade considered.

$$
D_{2 m, n T}=R^{\prime}+\Delta L_{f s}+10 \log \left(C_{s a b} \frac{T}{T_{o} S}\right)[d B]
$$

where:

- $\mathrm{R}^{\prime}$ is noise insulation;

- $\mathrm{T}$ is the reverberation time in the receiving environment, in seconds;

- $\mathrm{C}_{\mathrm{sab}}$ is the Sabine constant, in second per metre with $\mathrm{Csab}=0.16 \mathrm{~s} / \mathrm{m}$;

- $\mathrm{T}_{0}$ is the reference reverberation time, in seconds; for housing $=0.5 \mathrm{~s}$. 
- $\Delta \mathrm{L}_{\mathrm{fs}}$ is the level difference due to façade shape, in decibels;

- $\mathrm{V}$ is the volume of the receiving environment, in cubic meters.

\section{Verifications in situ}

The experimental measurements in situ are carried out according to the reference international standards. This set of standards deals with the "Evaluation of sound insulation in buildings and building elements", both in terms of airborne noise and foot traffic. With the same set it is possible to draw from the frequency spectrum of the different parameters, the assessment indexes in terms of a single number. The values of such indexes are usually used in the different countries for the legislative audits. The calculation model, in addition to the equations that allow the treatment of experimental results, includes all the procedural rules to carry out the measurements according to the features of environments and their geometry. From the application of these rules a list, showing the number of minimum microphone positions necessary to perform each instrumental test, is obtained. The details of the calculations by the model are better described in the following chapter which specifically deals with the analysis of the BIM model in the experimental measurements phase. The following are the main equations, referred to experimental data, implemented in the calculation code:

$$
R^{\prime}=L_{1}-L_{2}+10 \log \left(\frac{S}{A}\right)[\mathrm{dB}]
$$

where:

- $\mathrm{S}$ is the area of the dividing element, expressed in $\mathrm{m}^{2}$;

- $\mathrm{A}$ is the equivalent sound absorption area of the receiving room;

$$
L_{n}^{\prime}=L_{i}+10 \log \left(\frac{A}{A_{0}}\right)[\mathrm{dB}]
$$

where:

- $\mathrm{A} 0$ is the equivalent reference absorption area, equal to $10 \mathrm{~m} 2$,

- A the equivalent area of sound absorption in the receiving environment.

$$
D_{2 m, n T}=L_{1,2 \mathrm{~m}}-L_{2}+10 \log \left(\frac{T}{T_{0}}\right)[\mathrm{dB}]
$$

where:

- $\mathrm{L}_{1,2 \mathrm{~m}}$ è il livello medio di pressione sonora alla distanza di $2 \mathrm{~m}$ dalla facciata, in decibels;

- $\mathrm{L}_{2}$ is the average sound pressure level in the receiving environment, in decibels;

- $\mathrm{T}$ is the reverberation time in the receiving environment, in seconds;

- $\mathrm{T}_{0}$ is the reference reverberation time, equal to $0.5 \mathrm{~s}$.

The equations here shown are used to manage the data obtained as a result of instrumental tests. They are implemented in the developed calculation model.

\section{Analysis of the BIM model for the test phase}

Taking advantage of the geometry and information from the BIM model, the instrumental survey is carried out. The minimum number of elements to be subjected to instrumental verification to test and / or classify the construction is a function of the verifiable elements. The instrumental survey phase, requires a phase of preparatory study during which all the elements to be tested are identified in compliance with the followed standards. In the preparatory phase, the following points are dealt with, taking considering environment by environment and according to the respective boundary conditions:

- Number of microphone positions used to perform each test.

- Volume of source and receiving environments;

- Room and geometry surfaces;

- Check of the rooms overlapping or tiling;

- Geometry of façade elements

All the information obtained in this way should be attributed to the measuring instrument, in order to perform the individual checks and to guarantee the certified measurement chain. The developed calculation model performs these operations by analyzing the BIM model and proposes on screen a vertex of verifiable elements with the relative peculiarities of each single measure. Then it will generate a file in Excel format with the measurement cards populated with all the information necessary to receive data from the instrumentation. In figure 6 this procedure is schematised.

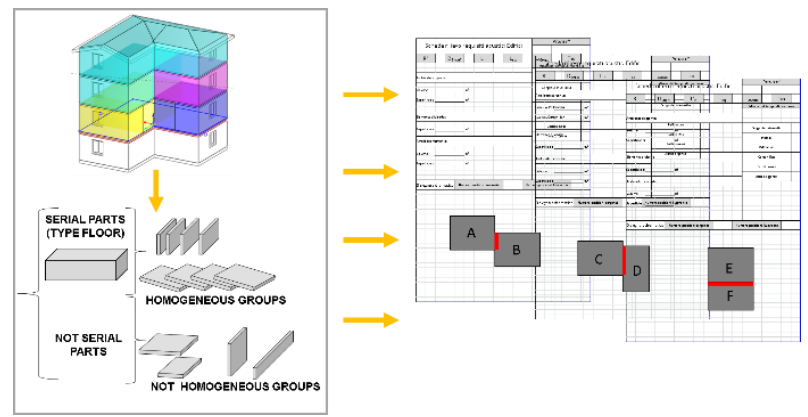

Figure 6: Preliminary analysis of the model for measurements and production of coded survey cards.

Once the preliminary analysis phase has been completed, the different measurements are carried out. In turn once the measuring cycles have been completed, it is necessary to associate the instrumental data to the BIM model in order to be able to proceed with calculations and determine the acoustic classification of the building. If the BIM model has been specifically and diligently coded, and this coding has also been reported in the instrumental apparatus, the allocation of measurements to the various elements can be performed automatically by the model. In the absence of coding it will be necessary for the operator to execute this process manually. Figure 7 shows the passage of instrumental data from the instrument software to the calculation model. 


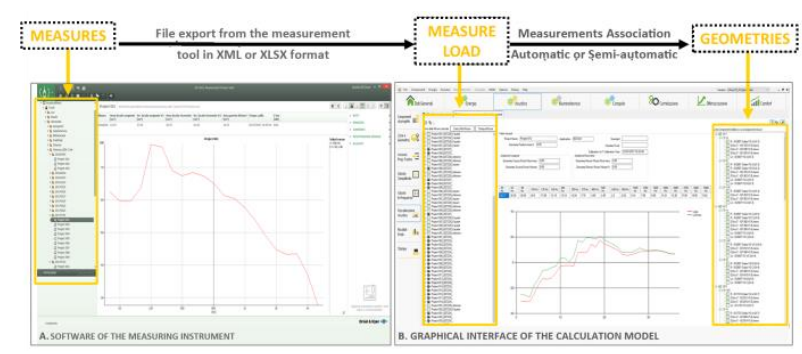

Figure 7: Preliminary analysis of the model for measurements and production of coded survey cards.

Figure 7 shows how the instrumentation software displays the various taken measures in form of a treeview. All the measurements can be usually exported in different formats, in this case those from Bruel \& Kiaer mod 2270 analyzer were used, the instrument software is called Measurement Partner Suite and allows an export in xslx and $\mathrm{xml}$ format. The interface implemented in the model allows the reading of information from the export file and the representation by an internal treeview from which it is possible to allocate the measurements to the geometries automatically or semi-automatically with the Drag \& Drop technique.

\section{Coding of the model and its importance}

If the BIM model has been appropriately codified, by assigning the appropriate unique identifiers to the rooms or simply using the GUID (Globally Unique Identifier) of IFC Space and IFC Elements, it is possible to assign to each measure a unique code that identifies the involved rooms and the elements subject to test. This subsequently allows an automatic assignment of measurements to the geometries obtained from the digital model. Figure 8 shows example the rooms coding in the BIM model.
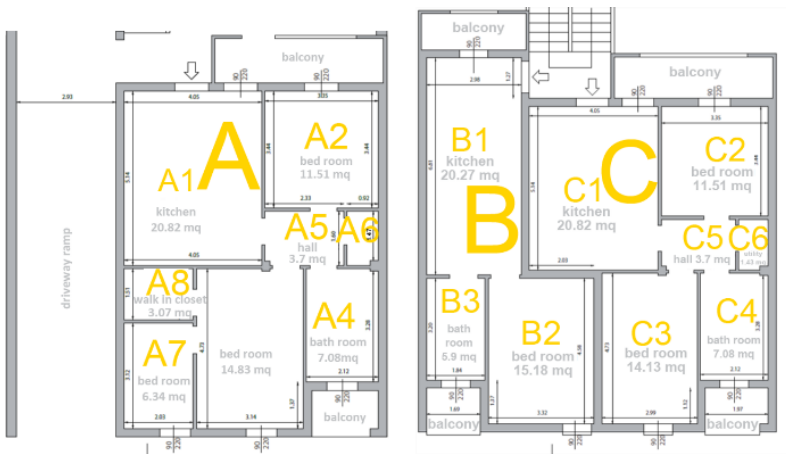

Figure 8: Example of encoding used for rooms.

As reported previously in the introduction, encoding can done in different ways and by different techniques. In case of complex or large-scale projects it is better to use a coding system which would be accepted by all the actors of the process capable of describing all the different stages and the various aspects, for instance the UNICLASS coding developed by NBS. In this respect long ago many authoring tools have the possibility of using plug-ins that enable the utilisation of the most known coding systems in an automated way.

\section{Association of results to the model}

After processing the individual measures, for example, to classify a real estate units or to assess the performance of individual elements, it is possible to allocate the results to the BIM model, closing in this way the cycle. This is achieved with the model by creating a dedicated Pset (Property Set) of data as encoded by the BuilfingSMART specifications for the interoperable IFC data format. The Pset created is identified with the abbreviation "Pset_XXXAcousticRequirements" where "XXX" indicates the considered element. Table 1 shows the Pset names currently managed by the model, referred to the various elements.

Table 1: List of Pset names for acoustic data.

\begin{tabular}{|c|c|}
\hline Name Pset & Element IFC \\
\hline Pset_SpaceAcousticRequirements & IfcSpace \\
\hline Pset_WallAcousticRequirements & IfcWall \\
\hline Pset_SlabAcousticRequirements & IfcSlab \\
\hline Pset_RoofAcousticRequirements & IfcRoof \\
\hline Pset_DoorAcousticRequirements & IfcDoor \\
\hline Pset_WindowsAcousticRequirements & IfcWindows \\
\hline
\end{tabular}

Finally, the process ends with the operation shown in figure 9, consisting of the assignment of the Psets described above to the related components through the use of a BIM Authoring Tools tool.
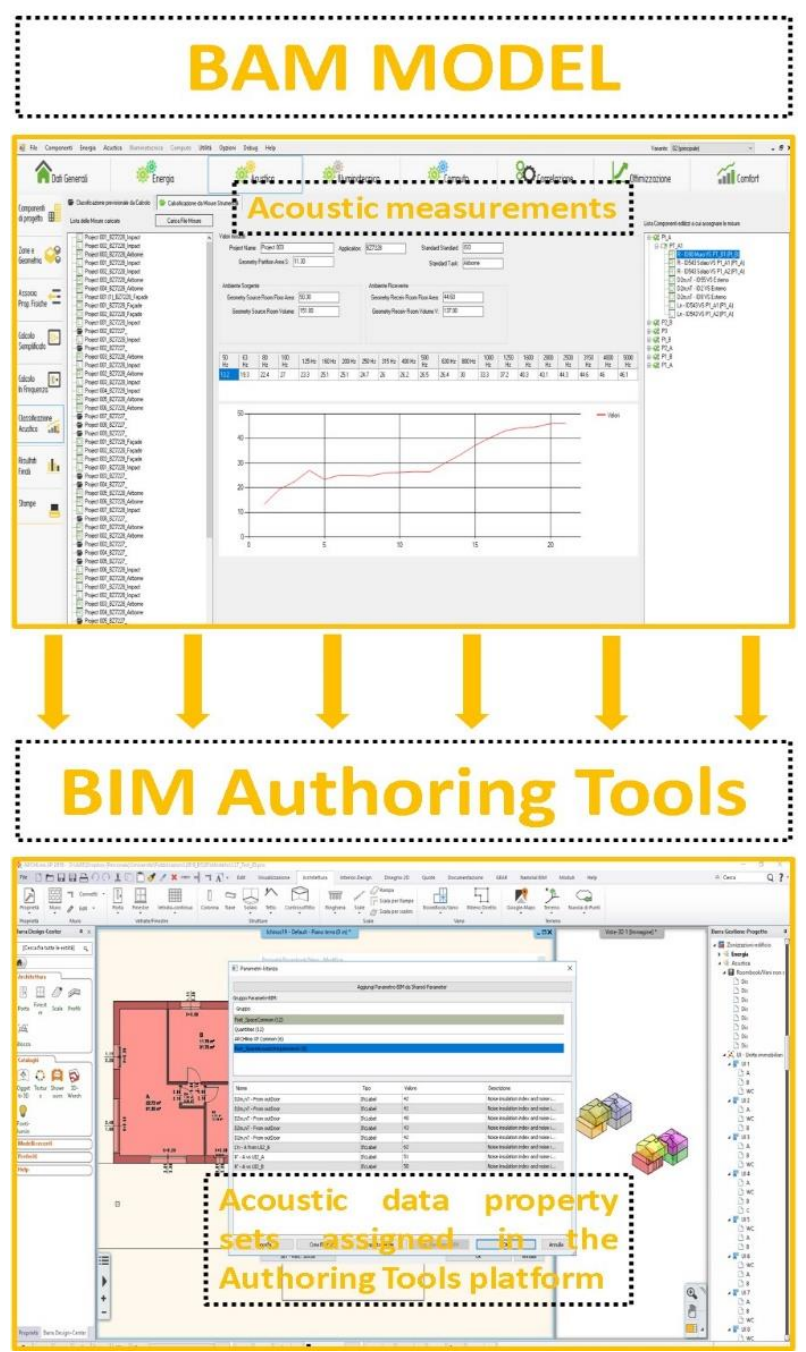

Figure 9: Assignment of the measurements results to the IFC model through the use of BIM Authoring Tools. 
In the present work the BIM Authoring Tools tool named ArchLineXP BIM (Cadline, 2018), developed by Cadline ltd and certified by BuildingSMART (buildingSMART, 2018), has been used.

\section{Tests carried out on the model and code checking}

The model described in the present work was tested on a real case of which both the design and construction phases were analysed for research purposes (Di Bella et al., 2017). The tests concerned the BIM modeling of the case study and the measurements performed in its different phases:

- initial phase

- intermediate phase

- final phase

The graphic representation of the model in its different phases is shown in figure 10 .

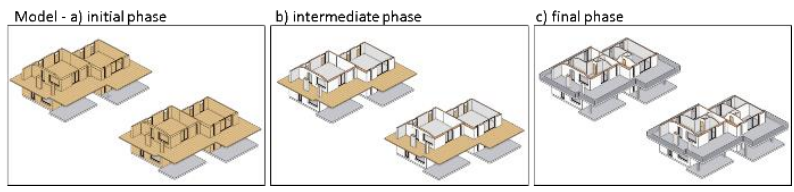

Figure 10: Phases of the case study.

For each phase, the predictive calculations were carried out starting from the BIM model and the checks in situ to go on with the subsequent processing and assignment of the Pset to the BIM model. At the end of each phase, a code checking was performed by processing the check tables displayed on screen and / or saved on Excel sheets as shown in Figure 11

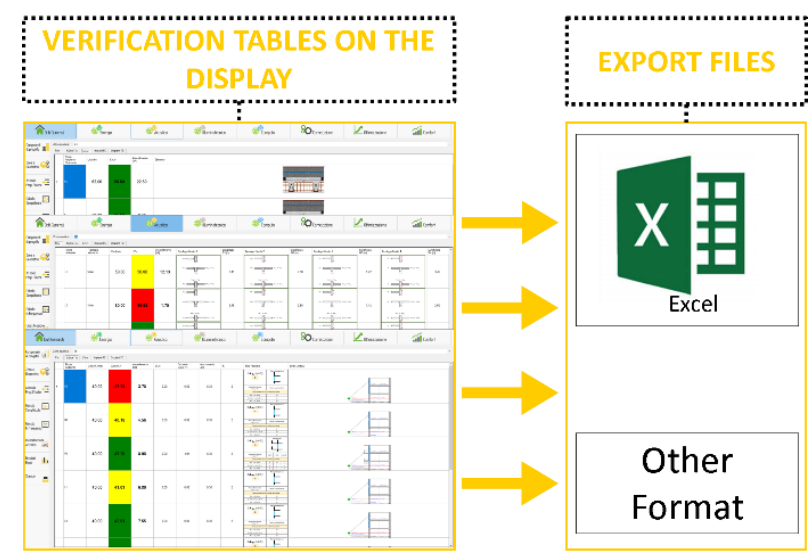

Figure 11: generating reports following the Checking quеие.

The information shown in the tables can in turn be associated with the model for a given phase.

\section{Conclusion}

The BIM methodology applied to the design and verification of the acoustic requirements of buildings has been analyzed. The developed calculation code refers to different regulatory standards, it is implemented as a Windows Application to allow the assessment of the high potential, both in the calculation and verification phase, resulting from the huge amount of geometric and informative data available with a BIM model. The most important aspects that have emerged in the experimental testing consist of highlighting the fundamental role that the coding system has to guarantee the interoperability among different software working tools. In conclusion, the code checking performed on the case study has shown how instrumental investigations succeed in highlighting the acoustic characteristics of the building during all phases of construction and testing, improving the final result in terms of quality. Research has been addressed to the analysis of benefits that the use of BIM methodology provides for the purposes of the procedures for predictive calculations and instrumental verification of buildings; computational results achieved both the design stage and in carrying out final test have been neglected to some extent as already developed elsewhere for the same test case (Di Bella A. 2017). The results obtained in terms of time to run a simulation, and of time to gather the data needed to instrumental verifications, lead to the conclusion that, without any doubt, the use of BIM procedures for acoustic purposes speed up and improve the design and verification process and its quality. Furthermore if the model is properly encoded and all the actors of the production process share the encoding, several processes can be further accelerated and automated, reducing errors and times just for their execution. For the next future we think about extending the model approach to other subjects, which include both predictive calculations and instrumental verifications, namely those concerning energy and lighting engineering in the case of a multi-objective model.

\section{Acknowledgement}

This paper has been drawn up within the National Research Project funded by MIUR (PRIN 2016): Energy requalification of the existing building park towards nZEB (nearly Zero Energy Buildings)

\section{References}

Bazjanac, V., (2001) Acquisition of Building Geometry in the Simulation of Energy Performance, Proceedings Building Simulation 2001, 7th International IBPSA Conference, Rio De Janeiro.

Di Bella, A., Mastino, C.C., Barbaresi, L., Granzotto, N., Baccoli, R., Morandi, F.,(2017). Comparative study of prediction methods and field measurements of the acoustic performances of buildings made with CLT elements, Proceedings of the InterNoise 2017, Hong Kong China, pp. 3555-3564(10).

Kim S. Y., Coffeen R. C. and Sanguinetti P., (2013). Interoperability Building Information Modeling and acoustical analysis software - A demonstration of a performing arts hall design process, Proceedings ICA 2013, Montreal, Canada.

Kirkegaard P. H. , Kamari A. (Edited by), (2017). Building Information Modeling (BIM) for Indoor Environmental Performance Analysis, 2017, Aarhus University, ISSN 2246-0942.

Marini M., Baccoli R., Mastino C.C., Da Pos V., Tòth Z., (2015). A new computational model: G.E.A.R. 
Graphical Expert Analytical Relations, Procedings of BSA 2015, Bolzano, Italy.

Marini, M., Mastino, C.C., Baccoli, R., Frattolillo, A., (2018), BIM And Plant Systems: A Specific Assessment, Energy Procedia, 148, 623-630.

Mastino C.C., Baccoli R., Frattolillo A., Marini M., Di Bella A., Da Pos V., (2017a). The Building Information Model and the IFC standard: analysis the characteristics for the acoustic and energy simulation of buildings, Proceedings of BSA 2017, Bolzano Italy

Mastino C.C., Di Bella A., Semprini G., Frattolillo A., Marini M., Da Pos V., (2017b). BIM application in design and evaluation of acoustic performances of buildings, Procedings of ICSV 2017, Hiroshima, Japan.

Richard A., Jon W., (2010), Integrating acoustical data into the Building Information Modeling using Industry Foundation Classes, 159th Proceedings of Meeting Acoustical Society of America/NOISE-CON 2010, Baltimore, Maryland.

Wu C.D,. Clayton M.J, (2013). BIM-Based Acoustic Simulation Framework, Proceedings of the 30th CIB W78 International Conference, 2013, Beijing, China.

International Organisation for Standardisation (2013). Industry Foundation Classes for data sharing in the construction and facility management industries ( ISO 16739)

International Organisation for Standardisation (2017). Building acoustics - Estimation of acoustic performance of buildings from the performance of elements - Part 1: Airborne sound insulation between rooms (ISO 12354-1).

International Organisation for Standardisation (2017). Building acoustics - Estimation of acoustic performance of buildings from the performance of elements - Part 2: Impact sound insulation between rooms (ISO 12354-2).

International Organisation for Standardisation (2017) Building acoustics - Estimation of acoustic performance of buildings from the performance of elements - Part 3: Airborne sound insulation against outdoor sound (ISO 12354-3).

International Organisation for Standardisation (2009). Building acoustics - Estimation of acoustic performance of buildings from the performance of elements - Part 5: Sounds levels due to the service equipment (ISO 12354-5).

International Organisation for Standardisation (2014). Acoustics - Field measurement of sound insulation in buildings and of building elements - Part 1: Airborne sound insulation (ISO 16283-1).

International Organisation for Standardisation (2015). Acoustics - Field measurement of sound insulation in buildings and of building elements - Part 2: Impact sound insulation (ISO 16283-2).

International Organisation for Standardisation (2016) Acoustics - Field measurement of sound insulation in buildings and of building elements - Part 3: Façade sound insulation (ISO 16283-3).

Ente nazionale italiano di unificazione (Italian Authority for Standardisation) (2010). Acustica in edilizia Classificazione acustica delle unità immobiliari Procedura di valutazione e verifica in opera (UNI 11367 ). (Building Acoustics - Acoustic clas-sification of building units - Evaluation procedure and in-situ measurements)

Ente nazionale italiano di unificazione (Italian Authority for Standardisation) (2012). Acustica in edilizia Classificazione acustica delle unità immobiliari Linee guida per la selezione delle unità immobiliari in edifici con caratteristiche non seriali (UNI 11444). (Acoustic classification of real estates in buildings with non serial elements)

Cadline Ltd, [Online.] (2018) available: https://www.archlinexp.com.

buildingSMART, [Online.] (2018) available: http://www.buildingsmart-tech.org/specifications. 